\title{
Urban and landscape design in the Arabian Gulf region: a new paradigm for sustainability
}

Robert Cooke BEng(Hons), MSc, EngD, CEng, MEI, PQP

Associate Director, Sustainability, BuroHappold Engineering, Bath, UK

Globally humans consume $150 \%$ of naturally replenished assets, which is unsustainable, but in parts of the Arabian Gulf region the figure is up to $\mathbf{2 0 0 0} \%$. Furthermore, the population of the region's cities is set to increase dramatically. As discussed in this paper, the growth will have an impact on urban buildings, spaces and surrounding environments as well as on the areas used to fuel and feed these populations and the products they employ. While this can never be truly 'sustainable' in the traditional sense, there is significant scope for inherent reduction in demands, massive efficiency gains and deployment of non-consumptive renewable resources. A new paradigm for sustainable design in the Gulf is proposed.

\section{Introduction}

This paper explores the current sustainable development challenges in relation to urban design in the Arabian Gulf region. There has been significant expansion of population, built-up area, gross domestic product and resource use in the region over the past 40 years. Unfortunately this growth has resulted in significant negative social and environmental impacts. There is a recognition from regional leaders that there must be a shift in thinking, planning and operation to reflect sustainability.

In February 2015 a conference was held in the United Arab Emirates (UAE) entitled Future Landscape \& Public Realm Abu Dhabi. This paper reflects on key points from this conference through the lens of identifying what sustainable landscape and urban design means in the Gulf. The conclusions drawn from the conference by the author is that a new design paradigm for sustainable landscape and urban realm in the Gulf region is required, which could be based on the following principles

- creating outside places that provide equity for people and nature

- recognising the need for sustainable design and a common definition

- understanding the role of different habitat types: natural and anthropogenic

- understanding the drivers for anthropogenic habitats

- understanding the difference between needs and wants

- analysis of synergies and conflicts in the context of sustainability.

These thoughts are illustrated through outlining key challenges for delivering against ideals, examples of regional case studies to inform solutions, showing how it is important to inspire decisionmakers and the public to embrace their role, and setting out initial common indicators that might lead to a framework for assessment.

\section{Outside places}

Put simply, 'landscape and public realm' means outside spaces, and there are two main types of these habitats: anthropogenic and natural. However, there are very few purely natural habitats not influenced by anthopogenic behaviour or control, with most habitats now a hybrid of the two. With increasing industrial, agricultural and forestry activity - and the consequential impacts of climate change and land, air and water pollution - human influence can be seen across all landscapes, forests and oceans.

There are clearly varying degrees to which the footprint of humans can be witnessed. There is a trade-off in terms of whether the dominant occupier of an outside place is on balance more for people (public realm) or for nature (landscape), although the reality is the majority of landscape has been utilised for people wherever it has a resource value.

The dominance of human influence is due to the lack of 'value' attributed to nature, natural habitats and ecological systems, with a focus on utilising natural capital as a resource for human means. This is exemplified in the Arabian Gulf region, where recent rapid development has largely had a general disregard for habitat types and habitat value. There is very little regulation around the area and equally insufficient research and understanding.

Some commentators have even described the deserts of the UAE as 'barren'. However, the desert habitats across the UAE and northern Oman peninsula are some of the most natural, untouched and unexplored habitats in the world. Recent studies of the peninsula have unearthed a vast array (around 10000 ) of species previously undocumented, and around 1000 species previously unknown to science. Habitats such as mangroves are recognised as being among the most critical habitat types on Earth.

The region's habitats are under-valued and need to be researched, understood and enabled to flourish. It is important to recognise the range of habitat classifications in the region and try to understand the role they play, their value and how they can be protected and enhanced. Society has to move away from the assumption that the approach of dredging, land reclamation and land clearing as a platform for artificial landscapes with nonindigenous planting and desalinated water features is acceptable. A positive example is the Sabah Al Ahmed Sea City project that, through careful engineering, increased the coastline of Kuwait by $100 \%$, providing development and social benefits as well as an increase in habitats and local biodiversity. 
Civil Engineering

Volume 171 Issue CE6
Urban and landscape design in the Arabian Gulf region: a new paradigm for sustainability Cooke

\section{Need for sustainable development}

Over 40 years ago Meadows et al. (1972) stated in their book The Limits to Growth, 'If no change is made in the trends of world population growth, industrialization, pollution, food production and resource exploitation, our planet's limits of growth will be reached sometime within the next one hundred years. The most probable outcome will be a sudden and uncontrollable decline both in population and in industrial capacity.' Since then, the growth in population and consumption rates has accelerated and consumption of resources has far exceeded practical limits.

Fifteen years later the World Commission on Environment and Development (1987) provided a seminal definition of sustainable development, in its report Our Common Future (Figure 1), as 'Development that meets the needs of the present without compromising the ability of future generations to meet their own needs.'

Also known as the Brundtland Report after the commission's chairman (Figure 2), it highlighted that 'sustainable development is not a fixed state of harmony, but rather a process of change in which the exploitation of resources, the direction of investments, the orientation of technological development, and institutional change are made consistent with future as well as present needs. We do not pretend the process is easy or straightforward. Painful choices have to be made. Thus in the final analysis, sustainable development must rest on political will.'

Commonly, sustainable development has been defined by the Venn diagram from the Royal Academy of Engineering (2005) in Engineering for Sustainable Development: Guiding Principles (Figure 3). However, this tends to ignore complexities, interrelationships and the concept of limits of capacity. These are more strongly defined in The Five Capitals Model from Forum for the Future (2007), which was adopted by the UK government and provides a hierarchy to the theory (Figure 4).

The model shows that the basis of development is natural capital. The development of social and human capital is dependent on the availability of natural capital and the efficiency of its use. This then forms the basis for the development of financial and manufactured capital and puts into perspective the principles of

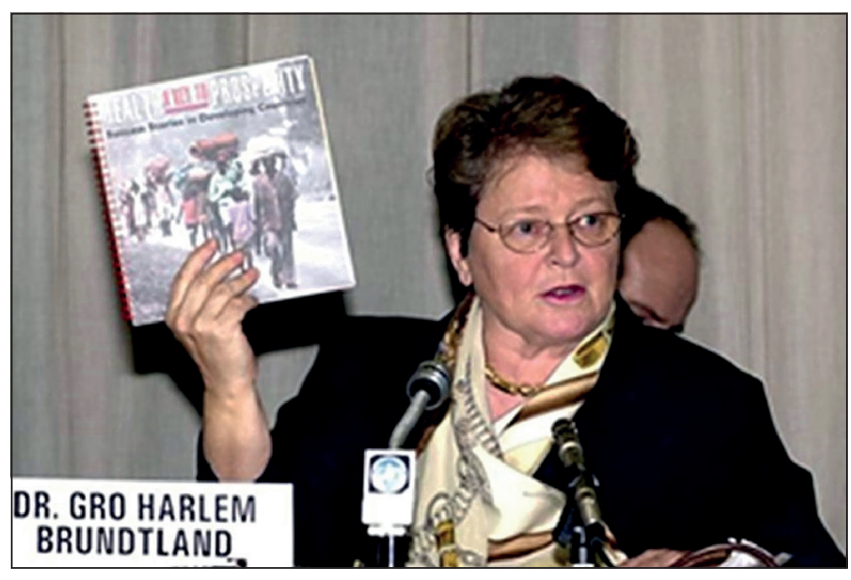

Figure 2. Then Norwegian prime minister Gro Harlem Brundtland chaired the World Commission on Environment and Development report Our Common Future

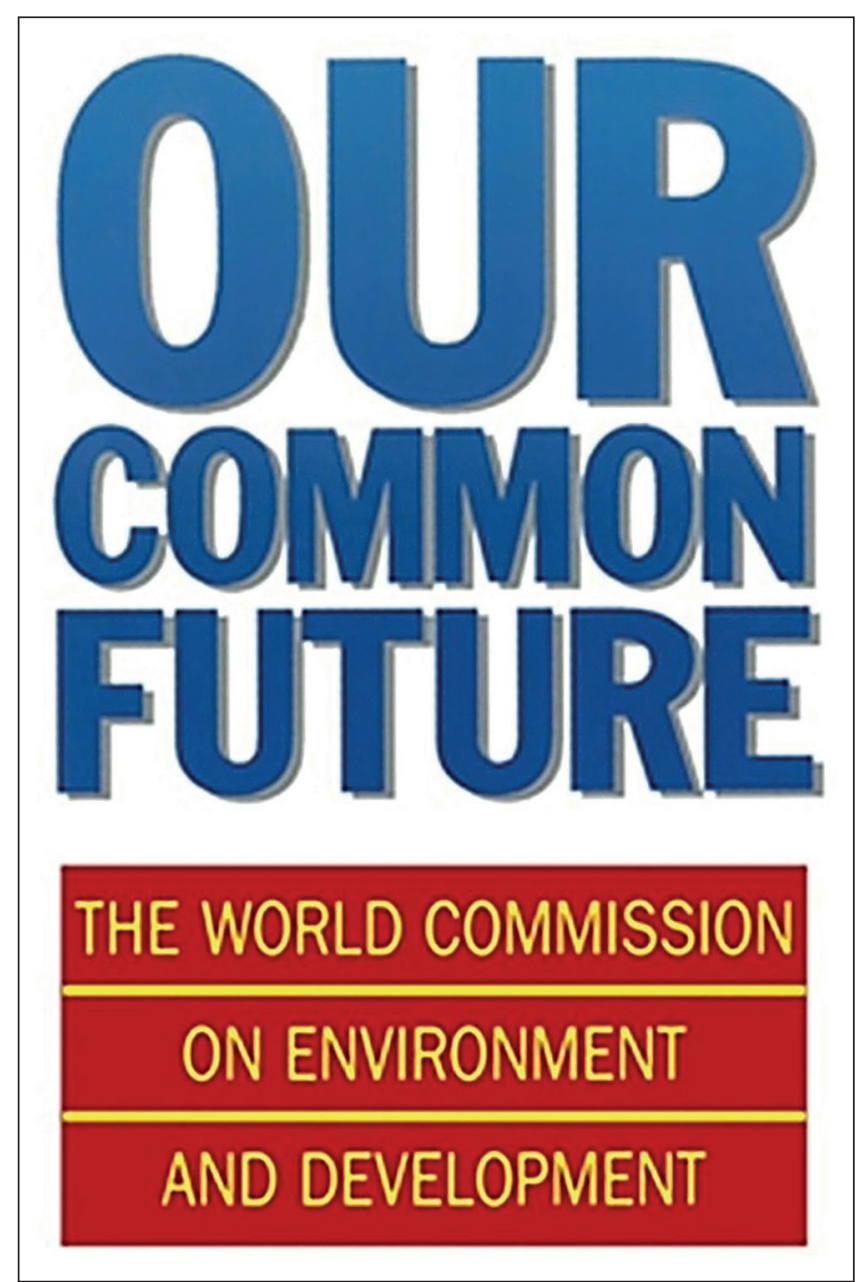

Figure 1. World Commission on Environment and Development's Our Common Future report of 1987 provided a definition of sustainability

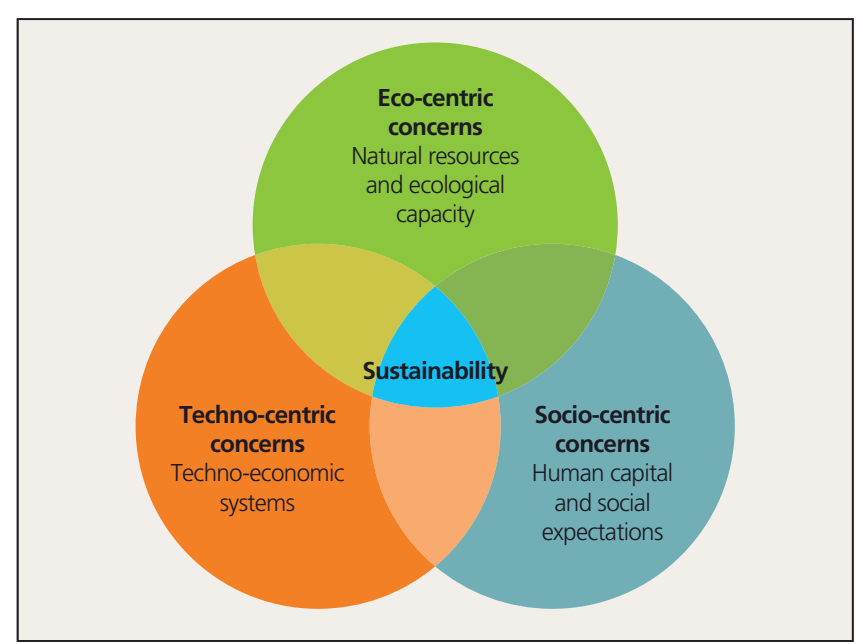

Figure 3. Venn diagram for sustainable development from the Royal Academy of Engineering's Engineering for Sustainable Development: Guiding Principles 


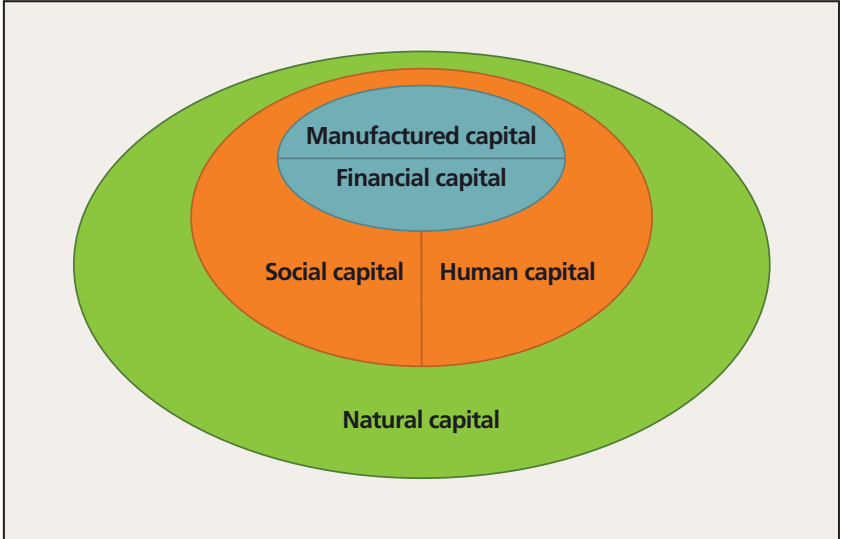

Figure 4. The Five Capitals Model (Forum for the Future, 2007)

limits to growth. The five capitals model also includes the concept of stocks and flows, which is useful for recognising the linkages between capacity and outputs.

Sustainability refers to the ability to survive in the long term. As such, sustainability can be defined as having two core aspects: human and environmental. The 'stuff' people build and own is temporal and money is a means of trading resources and has no physical capital. To be able to survive and flourish, humans need to protect themselves and the environment. Economic sustainability is a function of natural and social capital and how they are deployed, and, as such, should be considered as a desirable consequence of human and environmental sustainability.

\section{Sustainable development in the Arabian Gulf}

Environmentally and socially the Arabian Gulf region is in an alarming state. It is heavily dependent on fossil fuel use and impoverished and disempowered labour living in poor conditions. Land-use planning and the design of outdoor spaces are major contributing factors, in which there is significant and largely unnecessary environmental damage due to land-use practices and landscape irrigation.

From a broad-spectrum perspective, the Zoological Society of London and WWF (2014) Living Planet Index has been used consistently for the measurement of ecological footprints for a sustained period. It provides a useful assessment method for understanding relative impacts, tracking change, reviewing trends and for target sending. Using this tool the current (published) ecological footprint of Gulf countries is estimated to be as follows

- Kuwait - 9.72 global ha per capita

- Qatar-11.68 global ha per capita

- Saudi Arabia - 3.99 global ha per capita

- UAE - 8.44 global ha per capita.

When considered in relation to a global average biocapacity of $1 \cdot 8$ global ha per person (and a much lower regional biocapacity),

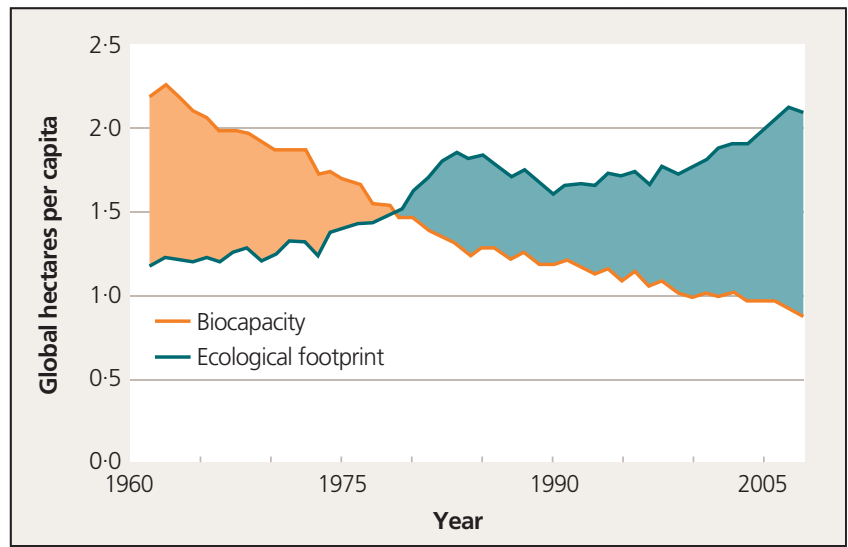

Figure 5. How the ecological footprint and biocapacity of Arab countries has changed since 1961

there is clearly over-consumption and a reliance on imports of resources. It should be noted that this method does not take into account the environmental impact of import (or transport) of goods such as food, which the region is heavily reliant on. It can be seen from Figure 5 how the ecological footprint and biocapacity of Arab countries has changed since 1961, with parity exceeded around 1978 (AFED, 2012).

Approximately two-thirds of the registered ecological footprint of Gulf countries is carbon dioxide emissions, and these have been the main growth factor since the records began. The remaining emissions largely relate to the interrelation between food production, fishing and consumption, stemming from the use of artificial fertilisers, a scarcity of groundwater, increasing reliance on desalinated water and use of fossil fuel for each step in the production and supply chain. The relationships are also linked further due to the need for water for fossil fuel extraction and heat rejection. Although the footprint of food production is relatively low, the environmental costs of food imports are not accounted for and remain partly hidden.

The water supply and usage picture is an alarming indicator of the challenges. Taking the UAE as an example, total water demand in 2007 was equivalent to $916 \mathrm{~m}^{3} / \mathrm{capita} /$ year (25101/ person/d) with over $80 \%$ estimated to be used for irrigation (Figure 6). Meanwhile the country is registered as having severe water scarcity (Figure 7) with only $16 \mathrm{~m}^{3} /$ person equivalent of renewable water resource each year. (Figure 8; FAO, 2016; Gassert et al., 2012).

Across the Gulf region, the local biocapacity is being reduced at an alarming rate. Demand now far outstrips supply leading to increasing levels of environmental debt. To repay this debt requires a significant reduction in demand. With increasing population levels and changes in average human lifestyle and expectations - moving towards high environmental intensity protein-rich diets, space-conditioning, automotive transport, global travel and so on - there are huge pressures on the ability to sustain development in the medium to long term. To do so will require significant shifts in government policies, human behaviours and expectations, system efficiencies and the principles of (product) design and development. 
Civil Engineering

Volume 171 Issue CE6
Urban and landscape design in the Arabian Gulf region: a new paradigm for sustainability

Cooke

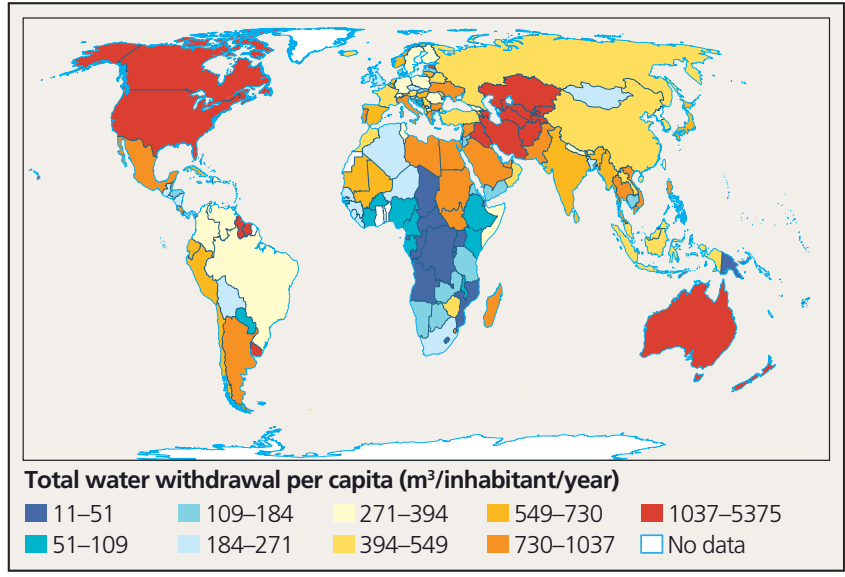

Figure 6. The UAE used an average of $916 \mathrm{~m}^{3}$ water per person in 2007

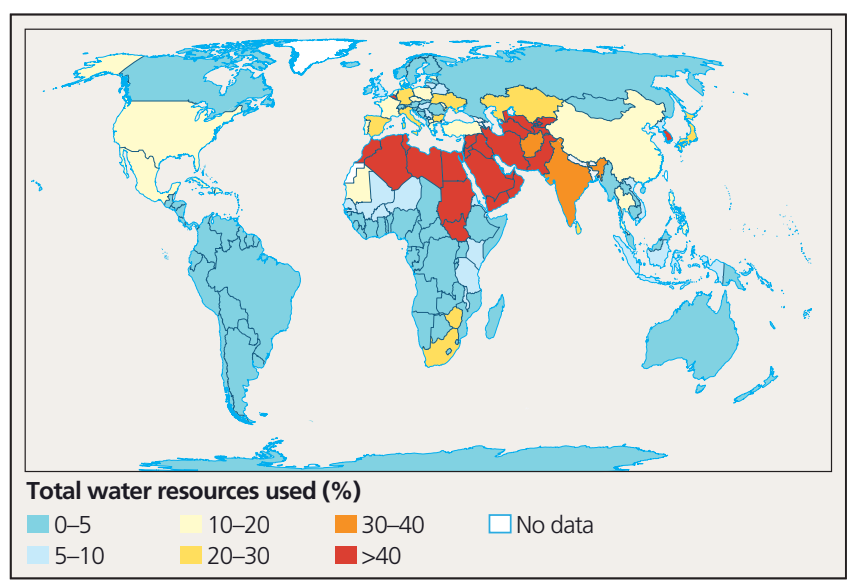

Figure 7. UAE used over 20 times its water resources in 2007

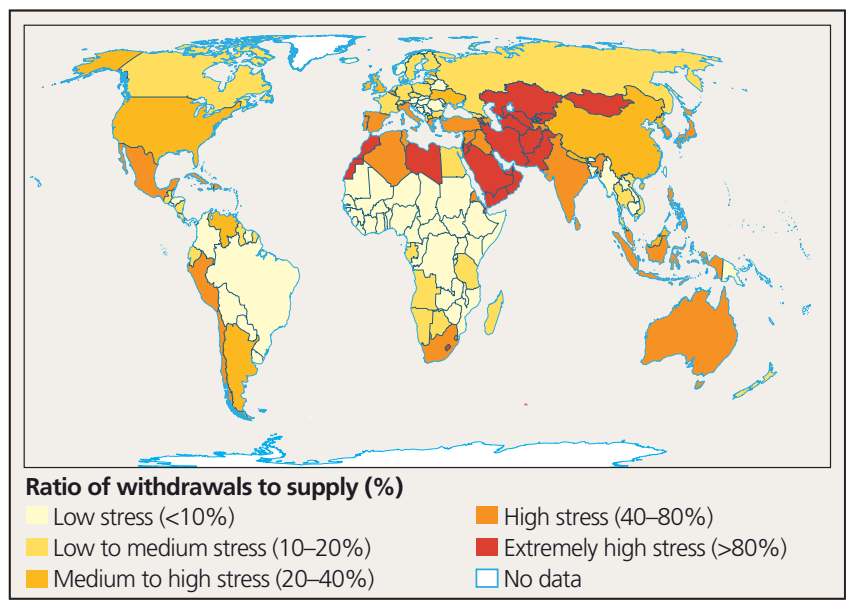

Figure 8. Water stress in the Arabian Gulf region is classed as 'extremely high' (>80\%)
Some of the key issues and consequences are as follows.

- Lack of understanding and policy measures that recognise the interlinkages between resource supply and demand issues, such as the energy-water-food nexus.

- Increasingly hostile urban environments - climate change and urban heat island.

- Air pollution levels - Qatar and UAE are in the ten worst countries for air pollution, with high residues of micro-toxins.

- Water pollution levels (in particular nitrification) from treated sewage effluent being pumped into the sea, lakes and ground - Qatar pumps $100000 \mathrm{~m}^{3} / \mathrm{d}$, but only $33 \%$ of wastewater was reused across the region in 2011.

- Sewage sludge disposal - waste dumps, leaching into groundwater.

- Water scarcity and nutrient overload in watercourses.

- Lack of diversity of plant cultures and increasing dominance and impact of pest species.

\subsection{Energy-water-food nexus}

An important factor in the evaluation of sustainability is interrelationships between issues. Within economies such as the Gulf region, where fossil and mineral resources are such a key factor in the economy on one hand, while also distinctly scarce on the other, the understanding of these relationships in the policy setting is key. Policies to encourage local agriculture to support food supply resilience, and keep prices low in the short term, have opposite consequences in the medium to long term if not considered from a holistic resource perspective.

Siddiqi and Anadon (2011) highlighted the presence and importance of the water-energy nexus across the region. Awareness of this nexus is growing globally but is particularly poignant for this region, where local economies are reliant on the presence of low-cost fuel and water and the trade exchange of fuel exports and food imports to support expanding cities.

In Saudi Arabia it is estimated that up to $9 \%$ of the total annual electrical energy consumption may be attributed to groundwater pumping and desalination. In the UAE this figure is closer to $20 \%$ of total electricity consumption for desalination, and these figures are rising as new desalination capacity is developed. This in turn increases domestic fossil fuel demand, reducing export volumes and revenues.

\subsection{Urban environments}

Current urban design practices prevalent in the Gulf give precedence to the car, with city areas typically allocating approximately $50 \%$ of the footprint area to roadways and surfacelevel car parking. A direct consequence of this practice is an increase in the heat-island effect and poor urban air quality (further incentivising personal car travel).

Meanwhile spatial planning disincentivises walking due to the prevalence of long walking distances in unwelcoming harsh, noisy and hostile environments. Unfortunately this is a self-perpetuating cycle as car-based planning prioritisation reduces the attractiveness of walking, cycling or the use of public transit. This leads to an increasing demand for road infrastructure, which only worsens the condition.

The dominance of the personal automobile in urban planning is subsequently having a significant negative effect on the health 


\section{Natural areas in Gulf cities are typically heavily diminished and disconnected. From a human perspective these are signified by epidemic levels of obesity, diabetes and heart disease together with high levels of respiratory conditions}

and well-being of both nature and humans. Consequences are that natural areas in Gulf cities are heavily diminished and disconnected. Then from a human perspective these are signified by levels of obesity, diabetes and heart disease that are at epidemic proportions, together with high levels of respiratory conditions.

\section{Starting again: setting a new paradigm}

Traditionally, the development of classic metropolitan areas was fed by the surrounding hinterland and a central water supply, such as a river or estuary. Each metropolis grew to a level that could be sustained by the natural and agricultural systems around it and was kept in check by short-term events triggered by poor sanitation, pollution, local supply shortages and so on.

However, since the onset of motorised transit, centralised water treatment and energy infrastructure and efficient goods distribution (termed 'petropolis' by the World Future Council), these towns and cities have been able to grow far in excess of their local limits, stretching out their roots to much wider areas where negative impacts are removed from the doorstep. Without a natural shortterm feedback loop, there is potential for environmental overshoot on a regional and global basis.

The separation needs to be reversed. The utilisation and supply of resources cannot be solely provided by an ever-increasing hinterland - it needs to be integrated into the outdoor fabric of towns and cities. It is important that even in urban areas people are connected mentally and physically to the stocks and flows of the natural world and to recognise and respond to the impacts of their lifestyles. The binary specialisation of land uses between landscape and the public realm needs to be recognised as a fallacy. All outdoor spaces should be seen as a hybrid role that values both people and nature in all cases.

\subsection{Drivers for anthropogenic habitats}

The volume of people living in cities and moving away from rural areas negatively affected by them is increasing, with immense growth in the percentage of city dwellers projected. Seemingly, this shift is taking humans from the outcome of the problem - where crops are failing and incomes are marginal - to the source of the problem, which will accentuate the issue further.

On reflection, the movement towards and creation of more intensive anthropogenic habitats has had the impact of removing the awareness of and connection with natural habitats. Despite a lower proportion of people living within or near to a natural habitat, the negative impact on nature has increased. If this continuation of poor resource management and creation of artificial habitats in cities is maintained, it is going to have an impact on the city spaces and surroundings themselves, but also on the areas used to fuel and feed these populations and the products they employ.

Principally, the root of the issue is that cities are a hugely unnatural intervention, creating high-density, mono-cultural environments - such as turf grass and palm tree boulevards - that have negative consequences. However, there are some recent examples in which interventions in cities have created positive habitats, and there are a number of reasons why a city's 'problem' can actually become the solution. These could include

high-density population

- high diversity of uses

- shorter travel distances

- cost-effective local embedded infrastructure

- reduced land take

- shared services (sports and recreation, etc.)

- short resource recovery cycles

- massive opportunities for investment and innovation

- global movements towards informed city leaders

- a shift towards 'smart' cities

- increasing awareness of key environmental issues such as climate change

- the ability to mobilise a social movement or obtain 'big data' through social media.

The following are what needs to be done.

- Better planning of mixed-use developments that effectively generate an internalised live-work-play function, obviating the need to commute to other areas.

- Replace development-oriented transit with transit-oriented development, which is designed around where development is created rather than the transport function being the reason for the development.

- Reduce centralised energy, water and waste infrastructure reliant on the import of generic or blended low-efficiency electricity and export of nutrient-rich wastewater and mixed municipal and commercial wastes.

- Reduce reliance on centralised transmission and distribution to deal with peaks and troughs in demand - instead localise the issue and create a feedback mechanism.

- Reduce reliance on external food growing and nutrient provision.

- Overcome social detachment from natural habitats and anthropogenic 'pseudo-natural' activities such as forestry and agriculture, thus creating ownership of issues such as food wastage.

- Increase city planning budgets, which are being cut in the light of increasing resource and maintenance costs.

- Ensure ageing infrastructure does not become more of a liability than an asset and restrict efficiency improvements.

- Use space more efficiently, given high land costs and property values.

- Recognise the difference between 'needs' and 'wants' and the impacts of delivering against these desires and balancing negative wider implications. 


\subsection{Difference between needs and wants}

Places need to be designed for people and for nature, so nature and people are the primary considerations for creating sustainable development. Beyond this rudimentary balance it is necessary to define within a brief or context the difference between needs and wants. Current levels of consumption and environmental degradation are well beyond the means of nature to replenish. From an urban design perspective there is a need to challenge the briefs and fundamentals of projects to delineate clearly what is needed for a sustainable future and the social 'wants'.

A typical example of a 'want' is a green, grassy median or carriageway shoulder that is predominantly for visual purposes. A common feature of transit corridors and junctions in the Arabian Gulf region is verdant green lawns and short-term ornamental planting irrigated daily and replaced regularly. The expectations of governments, municipalities, developers, residents and visitors need to be managed and it is critical to inform expectations and behaviours in relation to design and operation of a sustainable urban realm. In terms of decision-making, the value attributed to wider environmental needs must be increased beyond that of aesthetic expectations.

An example of the shift has been a change in policy within the Department of Municipal Affairs in Abu Dhabi, which is now in a third generation of urban design thinking. It has transgressed from a focus on visual aesthetic and 'greening' to a focus on increasing play and active spaces, through to a focus on reducing water use and maintenance requirements. This reflects the change in priorities and recognition of both the positive and negative role that urban green space can have in a Gulf city.

For instance, there has been a significant shift in the design of road medians from heavily grassed areas and palm trees to xeriscape indigenous low-level planting interspersed with lightcoloured stones, significantly reducing water and maintenance requirements.

The definition of the difference between needs and wants is an essential dialogue that needs to be created within society. It will help ensure that urban areas are designed in reflection of a deep understanding of needs and a recognition of knock-on consequences of providing to meet the 'wants' of society. This needs to include a recognition of personal individual motivations against those of a wider community or society. For this to happen, it is essential that there is an increase in participatory governance and a sense of community ownership over present and future consequences.

\subsection{Synergies and conflicts in the context of sustainability}

As per the definition from Bruntland, sustainable development requires difficult decisions to be made and the process of change to be embraced. This process of change can be considered to be an infinite challenge in the present context, in which even the best case studies and outcomes to meet current challenges will be likely to be deemed insufficient in the future.

However, there is opportunity to create a step change and really drive sustainable development through analysing design briefs and opportunities through the lens of enabling synergies and diluting conflicts. From a systems perspective, it is when mutual benefits between nature and humans can be captured that creates the most sustainable outcomes.
There is a prevalence of treating the provision of utilities and of achieving design objectives largely in isolation from each other, which may stem from how the industry is arranged, operated and governed. It is crucial that all areas of design are considered in a more integrated way. To help clients and design teams to do this, it is important to review issues from an integrated perspective with a multitude of stakeholders, with the aim of establishing potential synergies and interdisciplinary conflicts. This can start at a briefing level and progress through each stage of a design or evaluation project, but must be recognised as an important method for delivering broad sustainability and avoiding unnecessary costs.

An example of where the approach was used was in the initial briefing and conceptual design of the Masdar Zero Energy Villa concept with Masdar City and Woods Bagot. During this process all elements of the brief were drawn out and teams of multiple stakeholders (including Emirati residents) were asked to order them in terms of importance. Spatial requirements were recognised as an important requirement of the brief; however, so was the overall cost and a requirement for consumption efficiency and environmental responsibility.

It was therefore important to recognise the potential conflict, as a larger spatial area was likely to lead to increased material use and increased energy consumption. How this was overcome was through further evaluation of the 'need' for space and its purpose. By working together, the needs of both sides of the balance were explored and a synergy was created by delivering a higher proportion of useful space and future flexibility for expansion while minimising the conditioned area.

In the urban design context, many of the synergy and conflict issues stem from perspectives on movement, mobility and the personal automobile. An interesting synergy is the argument that closer, better connected, high-density mixed-use communities, where slow-movement local transit dominates, create much lower requirements for car use. This allows tighter streets, more interconnected green space, lower urban temperatures and lower development costs.

The conflict stems from a considered need (or even right) to own a car, which needs to be explored in detail and may relate to how movement happens between urban centres if destinations are not well served by sustainable urban design principles and transit means. Dubai is an excellent example of this conflict, where highly dense urban developments are poorly connected to each other by transit and where transit systems do not support lowspeed personal transit such as cycling. Bicycles are not allowed on the Dubai Metro network and stations are not served with cycle parking.

\subsection{Key challenges: delivering on promises}

As with building projects, there is a key risk with landscape and urban realm projects that the vision and plans will not come to fruition in the way intended. The majority of the 'impacts' of schemes is in the operation, yet this is likely to be where the designer has the least control. Experience has shown in the region that the design and selection of a low-water-use landscape may not be delivered to achieve target levels. Commonly, there is a disconnect between how a scheme is envisioned and what the contractors are incentivised to deliver and maintain.

For instance, landscape contractors are incentivised to ensure that planting is perceived as 'mature', to use minimal growing 
medium, to focus on short-term appearance and to provide more than enough water to ensure plants will not die while they are being established. These contractors often have to deliver a finished landscape within a very short period and have a clause to guarantee any plants that die within the first 2 years would be replaced free of charge. This contractual approach leads to short-term thinking in terms of plant selection, planting medium, irrigation strategy and maintenance.

Even where a low-water-use landscape has been specified, there is commonly no requirement to deliver the anticipated water-use levels. The contractors and maintenance teams will therefore take a cautionary approach to planting, heavily overwatering plants, which in turn do not establish mature root structures.

Some of the issues that need to be addressed include

- design of landscape and systems for long-term sustainability

- evaluation of construction and installation procedures, and a requirement to complete comprehensive commissioning and re-commissioning of infrastructure

- inclusion of performance targets within the contracts

- creation of operational feedback loops akin to post-occupancy evaluation, to ensure municipalities, owners, designers, operators and contractors learn lessons from existing systems

- review of operating and ownership models to incentivise more sustainable design and operation

- create a connection between city-scape 'users' and a means of participatory engagement

- create incentives for ongoing performance improvement

- recognise the economic value of wellbeing and of the services provided by nature in the design, delivery and operation of city-scape projects.

\section{Case study responses to inform solutions}

The following case studies provide a high-level perspective on some of the positive outcomes that can be delivered through taking an integrated development approach and through trying to create a balance between nature and humans in Gulf cities.

\subsection{Wadi Hanifah}

Wadi Hanifah is a $120 \mathrm{~km}$ long, $4500 \mathrm{~km}^{2}$ watershed to the west of Riyadh city. For more than 30 years up to 2002 the wadi was used for gravel extraction, sewage discharge, garbage dumping and construction waste. From years of misuse, the natural flood channel was interrupted with the result that flooding was a regular occurrence. The natural environment was seriously damaged and a potentially great resource was lost. This natural resource was being damaged with negative downstream environmental, human and economic implications.

Through the preparation and delivery of an environmental masterplan, implementation plan and management plan, the wadi was rehabilitated from an environmental and social hazard to become an economic, environmental and social asset. Construction of the first phase of this project was completed in 2010 and it was awarded the Aga Khan Award for outstanding rehabilitation of a damaged environmental asset. The improvements proved popular with city residents, resulting in more than 1 million people visiting in the first 6 months of opening.

Subsequently, the intervention led to a lower risk of flooding, provision of a social asset, rehabilitation of the natural asset and an increase in the economic value of land. Wadi Hanifah Park is now a stunning addition to Riyadh, providing much-needed recreational space for the community while enabling a sustainable future for the city's water use.

The success of Wadi Hanifah shows that urban green space can not only be successful in an arid environment such as Riyadh but, when delivered to a high standard, can become a defining character of the city environment. Wadi Hanifah now has its own identity.

\subsection{Wadi Aqeeq, Madinah}

As with Wadi Hanifah, human activity had degraded the natural capacity and function of Wadi Aqeeq valley, compromising ecology, hydraulic capacity and visual amenity. The degradation of the channel had significantly increased the risk of flooding to the city. Through a combination of upstream and wadi management improvements, using local materials and natural water management methods, the water course has been rehabilitated and reinvigorated. As a result the project has

- rehabilitated over $17 \mathrm{~km}$ of wadi

- created commercial opportunities

- created new visitor attractions such as the Al Ghab Nature Reserve, Urwah Place and the Oasis Park

- enabled residents and visitors to enjoy new areas of public realm, green infrastructure links and enhanced connectivity with tens of kilometres of shaded foot and cycle paths

- opened up to the public culturally historic features that were previously hidden

- delivered against the primary drivers of environmental rehabilitation, cultural vitality and economic prosperity.

\subsection{Masdar phase 2 detailed masterplan}

The original Masdar City masterplan had very grand aspirations for a car-free and 'zero carbon dioxide' city that was originally penned for completion by 2014 . However, since the original masterplan was produced and the initial stages of construction initiated, there were a number of changes to market conditions and subsequent client requirements. This led to a revision of the concept masterplan and subsequent requests from Masdar City to revise detailed masterplans for individual phases.

CBT Architects successfully bid for the redesign of the phase 2 masterplan and produced an award-winning design covering an area of 1 million $\mathrm{m}^{2}$. The key to its design approach and the subsequent awards was the ability to balance high environmental aspirations with economically viable delivery and a people-centred approach. CBT described it as a 'fine grained, pedestrian friendly and environmentally sustainable residential neighbourhood and a world class research and development cluster with major public spaces'.

The design of this development was founded on the concept of ensuring an approach is appropriate at the smallest scale, the individual experience, to the property developer and up to the masterplan operator. This was applied for technical details such 
Civil Engineering

Volume 171 Issue CE6
Urban and landscape design in the Arabian Gulf region: a new paradigm for sustainability

Cooke as the whole water balance perspective, to movement, energy, comfort and so on and across disciplines in an integrated manner.

Important features include careful plot and building design directives to ensure porosity and connectivity of the public realm by pedestrian transit and that these protected pathways would be shaded through overhanging roof canopies. This significantly reduces the cost of adding shade structures or lines of street trees, thus also reducing water demand.

External water use was carefully considered at each level to create a strong hydro-zoning hierarchy. There will be local oases of green within specified gathering spaces, with larger areas meeting xeriscape standards while also utilising features such as bioswales as part of the green and blue infrastructure strategy.

Across the project there was a high focus on ensuring the design was at the human scale and would enable and encourage use of external areas for walking and cycling in as many passive ways as possible. Car-based access was enabled at grade level, thus avoiding the need for an expensive undercroft network. In many areas this created synergies that would not only save money but also reduce material requirements, benefit the environment and improve the human experience.

\section{Summary and recommendations}

This paper explores the concept of sustainable urban design and landscape in the Arabian Gulf through capturing the outcomes of the Future Landscape \& Public Realm Abu Dhabi conference in Abu Dhabi in 2015. The key guidance from this for sustainable landscape and public realm in the Gulf is as follows.

Fundamentally, it is unsustainable to aim to provide any new manufactured habitats that rely on irrigation not naturally available, unless the water is available as some by-product of some existing human activity or intervention, as is the case with Wadi Hanifah.

Build with purpose - every element of the public realm should have a productive role. The brief should be challenged and an understanding gained of long-term needs over wants.

Long-term stewardship is the priority - the urban realm should be an income or value generator over time. Good urban landscape schemes require initial capital investment but the returns can be significant - although they may not all be captured by the original investors. Wadi Hanifah is a classic example.

A network of landscape and public realm should be created to facilitate transit of people and fauna. Connectivity is more important than vast central facilities from a social and environmental (habitat) perspective.

People-centred (pedestrian friendly) design and transitoriented development should be used rather than emphasis on car transport and parking. Ease of transit should be the catalyst for development, which should include microclimate creation to facilitate pedestrian transit, supported by multiple parameter crowd flow modelling to optimise experience.

Density is one element, but connectivity within and between dense areas (and balanced mixed use) is key, otherwise there is gridlock - for example, the Dubai Marina.

Irrigation demands should be balanced against treated sewage effluent availability generated by the surrounding buildings and optimised use. For this there needs to be a very good understanding (load and demand geodatabase, hydraulic models, etc.) that is verified and understood.

Plant types should be designed and selected to account for high levels of salinity in treated sewage effluent. Native vegetation is often only available in small sizes, so planning needs to be well in advance and self-grow. Growth of local plants should be enabled in situ and accidental plant growth encouraged rather than shortlived artificial planting. Bioswales and depressions should be included.

A network of food production should be created in line with treated sewage effluent supply networks. Seawater greenhouse or hydroponic systems should also be considered. Ideally, black water will be treated within a site and nutrients utilised locally, which includes systems such as a living machine.

Synergies and balance should always be looked for. Shade is expensive, infrastructure is expensive, so massing and land use can be planned to design out the need.

Finally, people should be inspired to change and make a difference and empower humans and nature to thrive together. This must include examining incentives for behaviour change from a design, construction, operation and lifestyle perspective.

\section{References}

AFED (Arab Forum for Environment and Development) (2012) Arab Atlas of Footprint \& Biocapacity. See http://www. afedonline.org/report2012/PDF/ English/9.pdf (accessed 27/05/2018).

FAO (Food and Agriculture Organization of the United Nations) (2016) AQUASTAT Main Database. See http://www.fao.org/nr/water/aquastat/ main/index.stm (accessed 14/06/2018)

Forum for the Future (2007) The Five Capitals Model - A Framework for Sustainability. See http://www.forumforthefuture.org/sites/defaultffiles/ project/downloads/five-capitals-model.pdf (accessed 27/05/2018).

Gassert F, Landis M, Luck M, Reig P and Shiao T (2012) Aqueduct Global Maps 2.0. World Resources Institute, Washington, DC, USA. See http:// www.wri.org/sites/defaultffiles/pdf/aqueduct_metadata_global.pdf (accessed 27/05/2018)

Meadows DH, Meadows DL, Randers J and Behrens W (1972) The Limits to Growth. Universe Books, New York, NY, USA.

Royal Academy of Engineering (2005) Engineering for Sustainable Development: Guiding Principles. See https://www.raeng.org.uk/ publications/reports/engineering-for-sustainable-development (accessed 27/05/2018)

Siddiqi A and Anadon LD (2011) The water-energy nexus in Middle East and North Africa. Energy Policy 39(8): 4529-4540

World Commission on Environment and Development (1987) Our Common Future. See http://www.un-documents.net/our-common-future.pdf (accessed 27/05/2018)

Zoological Society of London and WWF (2014) Living Planet Index. See http://livingplanetindex.org/home/index (accessed 27/05/2018).

How can you contribute?

If you would like to comment on this paper, please email up to 200 words to the editor at journals@ice.org.uk. If you would like to write a paper of 2000 to 3500 words about your own experience in this or any related area of civil engineering, the editor will be happy to provide any help or advice you need. 